\title{
The effect of fertility stress on endometrial and subendometrial blood flow among infertile women
}

\author{
Yuezhi Dong ${ }^{\dagger}$, Yanna Cai ${ }^{\dagger}$, Yu Zhang, Yurong Xing and Yingpu Sun ${ }^{*}$
}

\begin{abstract}
Background: To investigate the effect of fertility stress on endometrial and subendometrial blood flow among infertile women.

Methods: This case-control study was conducted in The First Affiliated Hospital of Zhengzhou University. The fertility problem inventory (FPI) was adopted to evaluate fertility stress. Three-dimensional power Doppler ultrasonography (3D PD-US) was performed during the proliferative phase of the menstrual cycle (days 5-11) to measure endometrial thickness, pattern, endometrial and subendometrial volume $(\mathrm{V}$ ), the vascularization index $(\mathrm{VI})$, the flow index $(\mathrm{FI})$ and the vascularization-FI (VFI) index. Then, 300 infertile women were separated into two groups (high-score group and low-score group) based on total FPI scores and 80 healthy women were selected as controls.
\end{abstract}

Results: No differences were found among all three groups with regard to general characteristics, endometrial thickness, pattern, endometrial and subendometrial V, VI and VFI. The endometrial and subendometrial Fls associated with different stress levels significantly differed among the three groups $(F=33.95, P<0.001 ; F=44.79, P<0.001$, respectively). The endometrial and subendometrial Fls in the control group were significantly higher than those in the high-score group and low-score groups. The endometrial and subendometrial Fls in the low-score group were significantly higher than those in the high-score group. The total FPI score was closely related to the endometrial and subendometrial Fls ( $r=-0.304, P<0.001 ; r=-0.407, P<0.001$, respectively).

Conclusion: Fertility stress was associated with endometrial and subendometrial flow index. Whether fertility stress might affect pregnancy outcome by reducing endometrial and subendometrial blood flow requires further research.

Keywords: Infertility, Stress, 3D power Doppler ultrasound, Subendometrial flow index

\section{Background}

Although in vitro fertilization (IVF) has helped many infertile couples become pregnant, those who choose to undergo IVF often suffer from the costs of medical treatment, the complexity of the procedures and unsuccessful cycles [1, 2]. Recently, researchers and clinicians have shown that psychological factors might reduce the chances of achieving pregnancy with IVF [3-5]. Previous studies have revealed a possible association between stress and reproductive outcomes. However, the specific pathways or mechanisms regarding how stress affects these

\footnotetext{
*Correspondence: syp2008@vip.sina.com

${ }^{\dagger}$ Equal contributors

Reproductive Medical Center, First Affiliated Hospital, Zhengzhou University, Zhengzhou, Henan, China
}

outcomes have not been conclusively identified. Most studies have suggested that anxiety and depression negatively affect sex hormone, neuroendocrine, or immunologic functions related to pregnancy failure [5]. Other studies have suggested that fertility stress causes poorer responses to ovarian function or decreases the number of retrieved oocytes in IVF treatment [6, 7]. Moreover, Zhao showed that restraint-induced stress inhibits mouse implantation by impairing uterine receptivity and down regulating oestrogen $(\mathrm{O})$ and progesterone $(\mathrm{P})$ and heparin-binding epidermal growth factor (HB-EGF) [8]. Castelrn proposed that fertility stress affects uterine artery blood flow, consequently influencing IVF pregnancy outcomes [9]. However, few studies have used endometrial receptivity to address fertility stress when evaluating 
pregnancy outcomes. Moreover, how fertility stress affects pregnancy outcomes through the neuroendocrine and immunologic systems remains unclear. Furthermore, histologic and molecular studies are invasive $[10,11]$.

Endometrial receptivity allows blastocysts to implant into endometrial tissue and grow successfully. Threedimensional power Doppler ultrasonography (3D PD-US) is a unique, non-invasive technique used to examine the vascularity of the entire endometrium or specific regions of interest [12]. Several sonographic parameters, such as endometrial thickness, pattern and volume $(\mathrm{V})$, as well as the endometrial and subendometrial vascularization index (VI), flow index (FI) and vascularization-flow index (VFI), have long been considered markers of endometrial receptivity in clinical practice [13-16]. Furthermore, excellent endometrial and subendometrial blood supplies indicate endometrial receptivity and are related to successful IVF outcomes [17].

Therefore, we hypothesize that alterations in 3D PDUS imaging demonstrates the reduction in endometrial receptivity due to fertility stress. Specifically, we (i) tested whether the endometrial thickness, pattern and 3D PDUS parameters are possible indicators of the association between fertility stress and endometrial receptivity; (ii) aimed to identify which 3D PD-US parameters are related to fertility stress. The 3D PD-US parameters in this study refer to endometrial $\mathrm{V}$ and the endometrial and subendometrial VIs, FIs and VFIs.

\section{Methods}

\section{Participants and eligibility}

This cross-sectional study was conducted on infertility women who first came to the First Affiliated Hospital Reproductive Medicine Centerof Zhengzhou University in Henan province. A total of 300 infertility women who were diagnosed with pure tubal factor and unexplained factor from June 2015 to June 2016 were enrolled in this study.(hysterosalpingography (HSG) and hysteroscopy were used as the criterion for diagnosing of tubal factors. 80 healthy women without fertility stress were selected as the control group at the Physical Examination Centerof the First Affiliated Hospitalof Zhengzhou University. All of the subjects (both infertility andhealthy women) follow the eligibility criteria: (i) aged 20 to 40 years old; (ii) self-reported menstrual cycle length of 21-39 days and in days 5-11 of their menstrual cycle; (iii) body mass index (BMI) less than $24.99 \mathrm{~kg} / \mathrm{m}^{2}$; (iv) No smoking; (v) No thyroid dysfunction, hyperprolactinemia, adrenal hyperthyroidism and other endocrine diseases,no hypertension, diabetes;(vi) and able to understand Chinese well enough to complete the questionnaires. The exclusion criteria were (i) hydrosalpinx; (ii) no use of hormonal drugs within the past three months; (iii) a history of pelvic surgery; (iv) the experience of a major life event over the past 12 months or have mental disorder. The Clinical Ethics Committee, First Affiliated Hospital of Zhengzhou University, approved this study.

\section{Assessment of fertility stress}

Perceived fertility stress was assessed using the fertility problem inventory (FPI) [18]. This measure shows satisfactory reliability and validity, with a Cronbach's alpha coefficient ranging from $0.77-0.93$. The Cronbach's alpha coefficient in this study was 0.79 . The inventory contains 46 items across 5 domains including social concerns, sexual concerns, relationship concerns, need for parenthood and rejection of a childfree lifestyle. Each item was scored on a 6-point Likert scale in which 1 denotes "I disagree" and 6 denotes "I totally agree". A greater total score indicated a higher level of perceived psychological stress. This inventory has been widely used as a screening tool in clinical practice [19]. The Mandarin version of the FPI (M-FPI) has been used effectively to evaluate infertile couples in China [20].

\section{Transvaginal 3DPD-US examination}

Given the variability associated with ovulation, all of the included women participated on menstrual days 5-11 to avoid additional selection variation. The patients and vaginal probe were kept as still as possible during the Volume acquisition. A single investigator performed all the examinations with a $5-$ to $9-\mathrm{MHz}$ endocavitary transducer using a Voluson E8 3D PD-US acquisition device (GE Healthcare, Kretz, Zipf, Austria) to avoid interoperator bias. First, endometrial thickness and endometrial echogenicity were visualized in 2D B-mode. The maximum thickness of the endometrium was measured via a longitudinal section at the maximum anteroposterior dimension. Then, the 3D PD-US mode was activated to ensure that the entire uterine Volume obtained included the entire subendometrium. The settings were as follows: sweep angle, $120^{\circ}$; quality, low; wall motion filter, low 1; pulse repetition frequency, $0.9 \mathrm{kHz}$; and rotating angles, $15^{\circ}$. As a result, 12 contour planes were obtained for each endometrium. Once the Volume measurement was complete, the manual mode of the virtual organ computer-aided analysis (VOCAL) software for the 3D PD-US histogram instrument was used to calculate the Volume and the VI, FI and VFI within the endometrium. The endometrial Volume was drawn by hand along the endometrial outline. The area of interest within the subendometrium was the region $10 \mathrm{~mm}$ from the endometrial border, and it was obtained via editing in shell imaging [21]. The subendometrial Volume, VI, FI and VFI were likewise calculated. The vascularization index, which representedthe density of vessels in the tissue and wasexpressed as a percentage. 
The flow index was thought to express the average intensity of flow. The vascularization-flow index was a combination ofvascularity and flow intensity.

300 infertile females were equally separated into two groups according to their total FPI scores: patients in the high-score group $(n=150)$ had higher total FPI scores, which means have greater fertility stress.whereas patients in the low-score group $(n=150)$ had lower total FPI scores,which means have lower fertility stress. A total of 80 healthy females served as controls. The sample size was calculated using PASS11.0 software(PASS 11 citation: Hintze J (2011). PASS 11. NCSS, LLC. Kaysville, Utah, USA). In this study,The power is $100 \%$ and the $p$-value, is set to be less than 0.05 .

\section{Statistical analyses}

All the data were analyzed using SPSS 17.0 (SPSS Inc., Chicago, IL, USA). A single factor variance analysis was used to compare the differences of age, infertility duration, examination date and 3D-power Doppler characteristics; Means and SDs were computed for all FPI scores. U Mann-Whitney test were performed to compare the different proportions of residence, types of infertility, infertility causes and childbearing history across the different levels of psychological stress. Compare 3 independent samples were run by single factor variance. Pearson correlation coefficient $(r)$ was used to determine the relationship between the FPI scores and the 3D PDUS characteristics. The significance level for all analyses was $P<0.05$.

\section{Results}

General information summarized in Table 1. The U Mann-Whitney testresults showed there were no differences among the 3 groups in terms of age, residence, infertility duration, infertility type, cause of infertility, childbearing history, examination date or menstrual cycle $(P>0.05)$.

Table 2 shows the FPI scores of infertility women. The total FPI scores of the high-score group were $186.60 \pm$ 17.931,ranging from 165 to 242 . The total FPI scores of the low-score group were $143.44 \pm 16.617$, ranging from 97 to 164 .

We also compared the clinical characteristics, including the endometrial thickness, volume, endometrial and subendometrial vascularization indexes, flow indexes, and vascularization-flow indexes. The scores of the three groups were similar in terms of endometrial thickness, endometrial and subendometrial Volume and vascularization index and vascularization-flow indexes $(P>0.05)$; however, the endometrial and subendome trial flow indexes significantly differed $(P<0.001)$. The endometrial and subendometrial flow indexes were significantly higher in the control group than in the high-score group and low-
Table 1 General characteristics for the three groups

\begin{tabular}{llll}
\hline Parameter & $\begin{array}{l}\text { Control } \\
(n=80)\end{array}$ & $\begin{array}{l}\text { Low-scoregroup } \\
(n=150)\end{array}$ & $\begin{array}{l}\text { High-scoregroup } \\
(n=150)\end{array}$ \\
\hline Age (y) & $31.5 \pm 4.6$ & $29.6 \pm 4.1$ & $30.1 \pm 4.5$ \\
Residence & & & $70(46.6 \%)$ \\
$\quad$ Urban & $41(51.2 \%)$ & $66(44.0 \%)$ & $80(53.4 \%)$ \\
$\quad$ Rural & $39(48.7 \%)$ & $84(56.0 \%)$ & $2.05 \pm 0.94$ \\
$\quad$ Infertility duration (y) & - & $1.91 \pm 0.80$ & \\
Type of infertility & & & $92(61.3 \%)$ \\
Primary infertility & - & $95(63.3 \%)$ & $58(38.6 \%)$ \\
Secondary infertility & - & $55(36.6 \%)$ & \\
Cause of infertility & & & $75(56 \%)$ \\
$\quad \begin{array}{l}\text { Female } \\
\text { Male }\end{array}$ & - & $34(22.6 \%)$ & $35(23.3 \%)$ \\
$\quad$ Mixed & - & $21(14.0 \%)$ & $16(10.6 \%)$ \\
$\quad$ Unexplained & - & $20(13.3 \%)$ & $15(10.0 \%)$ \\
History of childbearing & & & $20(13.3 \%)$ \\
$\quad$ Yes & $14(17.5 \%)$ & $24(16.0 \%)$ & $130(86.7 \%)$ \\
No & $66(82.5 \%)$ & $126(84.0 \%)$ & $9.61 \pm 2.20$ \\
Examination date, & $9.60 \pm 2.25$ & $9.68 \pm 2.22$ & \\
menstrual cycle (d) & & &
\end{tabular}

score groups. The endometrial and subendometrial flow indexes of the low-score group were significantly higher than those of the high-score group (Table 3 ).

Table 4 shows that the correlation coefficients between the need for parenthood,total FPI score and endometrial flow indexwere significantly different $(P<0.001)$. There were significant correlations between social concern, relationship concern, the need for parenthood, sexual concern, total FPI score and subendometrial flow index among infertile women $(P<0.001)$. However, the total FPI score, endometrial thickness and endometrial echogenicity, as well as the endometrial and subendometrial vascularization indexes and vascularization-flow indexes, were not significantly correlated $(P>0.05)$.

\section{Discussion}

Our study explored the effect of fertility stress on endometrial and subendometrial blood flow, providing a

Table 2 FPI scores of the infertility women

\begin{tabular}{lll}
\hline FPI scores & $\begin{array}{l}\text { High-score group } \\
(n=150)\end{array}$ & $\begin{array}{l}\text { Low-score group } \\
(n=150)\end{array}$ \\
\hline Social concern & $37.26 \pm 6.452$ & $26.61 \pm 6.388$ \\
Relationship concern & $36.55 \pm 7.449$ & $26.46 \pm 6.992$ \\
Need for parenthood & $50.53 \pm 6.366$ & $42.50 \pm 8.611$ \\
Rejection of childfree lifestyle & $34.81 \pm 7.361$ & $29.85 \pm 6.859$ \\
Sexual concern & $27.86 \pm 5.616$ & $18.02 \pm 5.710$ \\
Total & $186.60 \pm 17.931$ & $143.44 \pm 16.617$ \\
\hline
\end{tabular}


Table $\mathbf{3}$ The 3D PD-US characteristics of the three groups

\begin{tabular}{llll}
\hline Parameter & $\begin{array}{l}\text { Control } \\
(n=80)\end{array}$ & $\begin{array}{l}\text { Low-scoregroup } \\
(n=150)\end{array}$ & $\begin{array}{l}\text { High-score group } \\
(n=150)\end{array}$ \\
\hline $\begin{array}{l}\text { Endometrial } \\
\text { thickness (mm) }\end{array}$ & $7.38 \pm 2.07$ & $7.42 \pm 2.58$ & $6.93 \pm 2.31$ \\
$\begin{array}{l}\text { Endometrial } \\
\text { volume }\left(\mathrm{cm}^{3}\right)\end{array}$ & $2.36 \pm 0.97$ & $2.16 \pm 1.08$ & $2.33 \pm 0.97$ \\
$\begin{array}{l}\text { Endometrial } \\
\text { vascularization } \\
\text { index (\%) }\end{array}$ & $2.92 \pm 3.30$ & $3.43 \pm 3.93$ & $3.49 \pm 3.44$ \\
$\begin{array}{l}\text { Endometrial flow } \\
\text { index }\end{array}$ & $24.61 \pm 6.10^{* *}$ & $20.59 \pm 4.98^{* *}$ & $17.98 \pm 6.27^{* *}$ \\
$\begin{array}{l}\text { Endometrial } \\
\text { vascularization-flow } \\
\text { index }\end{array}$ & $0.75 \pm 0.96$ & $0.63 \pm 0.74$ & $0.69 \pm 0.73$ \\
$\begin{array}{l}\text { Subendometrial } \\
\text { volume }\end{array}$ & $33.17 \pm 7.54$ & $30.52 \pm 10.40$ & $31.30 \pm 8.10$ \\
$\begin{array}{l}\text { Subendometrial } \\
\text { vascularization } \\
\text { index (\%) }\end{array}$ & $9.93 \pm 8.10$ & $10.03 \pm 6.37$ & $9.64 \pm 5.01$ \\
$\begin{array}{l}\text { Subendometrial } \\
\text { flow index }\end{array}$ & $31.83 \pm 4.82^{* *}$ & $27.83 \pm 4.89^{* *}$ & $24.86 \pm 5.89^{* *}$ \\
$\begin{array}{l}\text { Subendometrial } \\
\text { vascularization-flow } \\
\text { index }\end{array}$ & $2.53 \pm 1.88$ & $2.62 \pm 1.59$ & $2.70 \pm 1.35$ \\
$\begin{array}{l}\text { **: P< } 0.001 \\
\text { Single factor variance was used to compare 3 groups of endometrial and } \\
\text { subendometrial blood flow indexs }\end{array}$ & & \\
\hline
\end{tabular}

comprehensive assessment that included endometrial thickness, endometrial pattern and Volume as well as endometrial and subendometrial VIs, FIs and VFIs. To the best of our knowledge, this study is the first to identify that the endometrial and subendometrial FIs significantly differed among these three groups and that fertility stress was correlated with endometrial and subendometrial FIs.
One study showed that neither age nor type of infertility affected endometrial or subendometrial blood flow [22]. However, other studies have shown that the FI is significantly lower among women older than 31 but significantly higher in mothers. The VI and VFI increased during the proliferative period and peaked three days after ovulation [23]. We compared the general characteristics among the 3 groups and did not find any significant differences. In addition, we compared the endometrial and subendometrial blood FIs, which were shown to significantly differ among the three groups. More importantly, we found that fertility stress was negative correlated with the endometrial and subendometrial FIs. Kupesic suggested that patients with greater endometrial FIs were associated with higher pregnancy rates [24]. This supposition is consistent with a study by Schild who also showed that subendometrial FI was the most important factor for predicting pregnancy outcomes [25]. Moreover, the correlation coefficient regarding the relationship between fertility stress and the endometrial FIs was less than that between stress and the subendometrial FI; this finding might be because the blood flow of the myometrium within the subendometrium directly affects the blood supply of the endometrium.

However, the mechanisms through which fertility stress affects the endometrial and subendometrial FIs remain unclear. we submit the following hypotheses. First, the activation of the stress response causes a series of neuroendocrine system reactions that are regulated by the two main neuroendocrine axes: the hypothalamicpituitary-adrenocortical (HPA) axis and the sympathetic adrenomedullary (SAM) system [26]. They are associated with increased concentrations of glucocorticoids and catecholamines [27]. Stress can excite catecholamines alpha receptors and cause vasoconstriction,

Table 4 The relationship between FPI scores and the 3D PD-US characteristics ( $r$ )

\begin{tabular}{|c|c|c|c|c|c|c|}
\hline & $\begin{array}{l}\text { Social } \\
\text { concern }\end{array}$ & $\begin{array}{l}\text { Relationship } \\
\text { concern }\end{array}$ & $\begin{array}{l}\text { Need for } \\
\text { parenthood }\end{array}$ & $\begin{array}{l}\text { Rejection of childfree } \\
\text { lifestyle }\end{array}$ & Sexual concern & $\begin{array}{l}\text { Total FPI } \\
\text { score }\end{array}$ \\
\hline Endometrial thickness & 0.048 & -0.044 & -0.027 & -0.02 & 0.06 & 0.006 \\
\hline $\begin{array}{l}\text { Endometrial } \\
\text { echogenicity }\end{array}$ & -0.029 & -0.018 & 0.034 & -0.052 & -0.11 & -0.043 \\
\hline Endometrial V & 0.105 & 0.009 & 0.081 & 0.025 & 0.020 & 0.072 \\
\hline Endometrial VI & 0.007 & 0.049 & 0.092 & -0.021 & -0.035 & 0.031 \\
\hline Endometrial FI & $-0.233^{* *}$ & $-0.220^{* *}$ & $-0.237^{* *}$ & $-0.153^{* *}$ & $-0.183^{* *}$ & $-0.304^{* *}$ \\
\hline Endometrial VFI & 0.016 & 0.077 & 0.088 & -0.028 & 0.012 & 0.052 \\
\hline Subendometrial V & -0.017 & -0.023 & 0.107 & 0.078 & -0.047 & 0.029 \\
\hline Subendometrial VI & -0.035 & 0.013 & 0.107 & -0.100 & -0.111 & -0.031 \\
\hline Subendometrial Fl & $-0.350^{* *}$ & $-0.313^{* *}$ & $-0.229^{* *}$ & $-0.195^{* *}$ & $-0.291^{* *}$ & $-0.407^{* *}$ \\
\hline Subendometrial VFI & -0.010 & 0.019 & 0.111 & -0.110 & -0.087 & -0.016 \\
\hline
\end{tabular}

$V$, Volume; VI, Vascularization index; FI, Flow index; VFI, Vascularization-flow index

**: $P<0.001$

Pearson correlation coefficient $(r)$ was used to determine the relationship between the FPI scores and the 3D PD-US characteristics 
thereby reducing uterusblood flow [9]. Second,Corticotropic-releasing hormone $(\mathrm{CRH})$ activates the HPA axis when stress is present in the body. Stress-induced HPA axis hyperfunction, causing hypothalamic-pituitaryovarianaxisaxis (HPO) dysfunction or disorder of which the most important effect is to reduce the Gonadotropin - releasing hormone $(\mathrm{GnRH})$ pulse secretion and then reduce the luteotropic hormone (LH) secretion. Moreover, CRH can not only reduce the basal level of estrogen but also inhibit Follicle stimulating hormone(FSH) synthesis of $\mathrm{O}$. When the levels of oestrogen drop, the uterine basal and spiral arteries contract, followed by a rise in peripheral vascular resistance. Blood flow distribution is then reduced [28]. Keratinocyte growth factor (KGF-2), which originates from uterine stromal cells, is upregulated by the action of $\mathrm{P}$. Slayden suggest that KGF-2 may affect embryo implantation and pregnancy outcome by increasing the blood supply to the myometrium and endometrium [29]. When the levels of P and KGF-2 drop, the blood supply to the endometrium and muscle layer decreases. Finally, stress can also cause persistent endothelial cell dysfunction,increase endometrial vascular permeability, reduced prostaglandin E2 (PG E2) release, leading to vasodilation decreased and contraction increased. Moreover, Carolpointed out that angiotensin II can promote endometrial vasoconstriction, resulting in blood volume decreased [30]. Bernatovasuggested that stress affects the neurotransmitter metabolism of Nitric oxide (NO), acetylcholine and serotonin, which eventually leads to decreases in the endometrial blood flow [31].

The present study has several strengths. First, our results provide new insights into the impact of fertility stress on pregnancy outcomes. Moreover, rather than creating an animal model, we used 3D PD-US and found that fertility stress was associated with endometrial and subendometrial FIs in women. Furthermore, we proposed a possible mechanism regarding how fertility stress affects the endometrial and subendometrial FIs, which provided a the oretical evidence for the impact of fertility stress on endometrial and subendometrial blood flow.

This study has several limitations. First, The limited number of FPI items made it extremely difficult to determine whether other factors affect fertility stress. Therefore, future studies that explore the role that stress plays on endometrial and subendometrial FIs should use a collection of stress biomarkers [32], and questionnaire data. Another weakness was our observational design. We only found that fertility stress is closely related to endometrial and subendometrial FIs. Whether stress affects pregnancy outcomes requires future longitudinal research. Finally, This study is only speculated and that the impact of fertility stress on endometrial and subendometrial blood flow lack direct evidence.

\section{Conclusions}

This study demonstrates that fertility stress is closely associated with endometrial and subendometrial FIs, but it is not related to endometrial thickness, type or endometrial and subendometrial VIs and VFIs. Fertility stress might reduce the endometrial receptivity by lowering the endometrial and subendometrial FIs. Therefore, we should pay more attention to women's fertility stress andto taking effective psychological interventions to reduce thefertility stress may help improve the pregnancy outcomes.

\section{Abbreviation \\ 3D PD-US: Three-dimensional power Doppler ultrasonography; BMI: Body mass index; CRH: Corticotropic-releasing hormone; Fl: Fow index; FPI: The fertility problem inventory; FSH: Follicle stimulating hormone; GnRH: Gonadotropin - releasing hormone; HB-EGF: Heparin-binding epidermal growth factor; HPA: The hypothalamic-pituitary-adrenocortical; HPO: Hypothalamic- pituitary-ovarianaxis; IVF: In vitro fertilization; KGF-2: Keratinocyte growth factor; LH: Luteotropic hormone; M-FPI: The Mandarin version of the FPI; N: Nitric oxide:; O: Oestrogen; P: Progesterone; PG E2: Prostaglandin E2; SAM: The sympathetic adrenomedullary; V: Volume; VI: Vascularization index; VFI: Vasculariza tion-flow index; VOCAL: The virtual organ computer-aided analysis}

\section{Acknowledgements}

This study was supported by the Physical Examination Department at the First Affiliated Hospital of Zhengzhou University for agreeing to support our research. We thank the people for their participation in this project. We also thank Feijing Zhou,Zhimin Sun and Yanan Song for their help in collecting the specimens. The language corrections in this study were made with the help of American Journal Experts (AJE).

\section{Funding}

No external funding was received for this study.

\section{Availability of data and materials}

All data supporting the conclusion of this article are included in thispublished article.

\section{Authors' contributions}

Professor YPS has designed the project and is the director during the process of conduction in this study. YNC, YZD and YZ were involved in the initial literature search, contributed to designing the draft, data interpretation and manuscript preparation. YNC and YRX were involved in reviewing the manuscript, data collection and statistical analysis. All authors read and approved the final manuscript.

\section{Competing interests}

The authors declare that they have no competing interests.

\section{Consent for publication}

Not applicable.

Ethics approval and consent to participate

All of the participants were recruited and approved by the Affiliated Hospital of Zhengzhou University Ethics Committee.

Received: 30 November 2016 Accepted: 24 February 2017

Published online: 04 March 2017

\section{References}

1. Polinder S, Heijnen EM, Macklon NS, Habbema JD, Fauser BJ, Eijkemans MJ. Cost-effectiveness of a mild compared with a standard strategy for IVF: a randomized comparison using cumulative term live birth as the primary endpoint. Hum Reprod. 2008;23:316-23.

2. Verhaak CM, Smeenk JM, Evers AW, Kremer JA, Kraaimaat FW, Braat DD. Women's emotional adjustment to IVF: a systematic review of 25 years of research. Hum Reprod Update. 2007;13:27-36. 
3. Gourounti K, Anagnostopoulos F, Vaslamatzis G. The relation of psychological stress to pregnancy outcome among women undergoing in-vitro fertilization and intracytoplasmic sperm injection. Women Health. 2011;51:321-39.

4. Sanders KA, Bruce NW. Psychosocial stress and treatment outcome following assisted reproductive technology. Hum Reprod. 1999;14:1656-62.

5. Pasch LA, Gregorich SE, Katz PK, Millstein SG, Nachtigall RD, Bleil ME, Adler NE. Psychological distress and in vitro fertilization outcome. Fertil Steril. 2012;98:459-64

6. Klonoff-Cohen $\mathrm{H}$, Natarajan $\mathrm{L}$. The concerns during assisted reproductive technologies (CART) scale and pregnancy outcomes. Fertil Steril. 2004;81:982-8.

7. Ebbesen SM, Zachariae R, Mehlsen MY, Thomsen D, Hojgaard A, Ottosen L, Petersen T, Ingerslev HJ. Stressful life events are associated with a poor invitro fertilization (IVF) outcome: a prospective study. Hum Reprod. 2009;24: 2173-82.

8. Zhao LH, Cui XZ, Yuan HJ, Liang B, Zheng LL, Liu YX, Luo MJ, Tan JH. Restraint stress inhibits mouse implantation: temporal window and the involvement of HB-EGF, estrogen and progesterone. PLoS One. 2013;8:e80472.

9. Castelan F, Xelhuantzi N, Hernandez-Aragon LG, Rodriguez-Antolin J, Cuevas E, Martinez-Gomez M. Morphometry of paravaginal ganglia from the pelvic plexus: impact of multiparity, primiparity, and pregnancy. Eur J Obstet Gynecol Reprod Biol. 2013;170:286-92.

10. Achache $H$, Revel A. Endometrial receptivity markers, the journey to successful embryo implantation. Hum Reprod Update. 2006;12:731-46.

11. Esmailzadeh S, Faramarzi M. Endometrial thickness and pregnancy outcome after intrauterine insemination. Fertil Steril. 2007;88:432-7.

12. Merce LT, Barco MJ, Bau S, Troyano J. Are endometrial parameters by threedimensional ultrasound and power Doppler angiography related to in vitro fertilization/embryo transfer outcome? Fertil Steril. 2008;89:111-7.

13. Kim A, Jung H, Choi WJ, Hong SN, Kim HY. Detection of endometrial and subendometrial vasculature on the day of embryo transfer and prediction of pregnancy during fresh in vitro fertilization cycles. Taiwan J Obstet Gynecol. 2014;53:360-5.

14. Chien LW, Lee WS, Au HK, Tzeng CR. Assessment of changes in utero-ovarian arterial impedance during the peri-implantation period by Doppler sonography in women undergoing assisted reproduction. Ultrasound Obstet Gynecol. 2004; 23:496-500.

15. Killick SR. Ultrasound and the receptivity of the endometrium. Reprod Biomed Online. 2007:15:63-7.

16. Zollner U, Specketer MT, Dietl J, Zollner KP. 3D-Endometrial volume and outcome of cryopreserved embryo replacement cycles. Arch Gynecol Obstet. 2012;286:517-23.

17. Kim A, Han JE, Yoon TK, Lyu SW, Seok HH, Won HJ. Relationship between endometrial and subendometrial blood flow measured by three-dimensional power Doppler ultrasound and pregnancy after intrauterine insemination. Fertil Steril. 2010;94:747-52.

18. Newton CR, Sherrard W, Glavac I. The Fertility Problem Inventory: measuring perceived infertility-related stress. Fertil Steril. 1999;72:54-62.

19. Van den Broeck U, D'Hooghe T, Enzlin P, Demyttenaere K. Predictors of psychological distress in patients starting IVF treatment: infertility-specific versus general psychological characteristics. Hum Reprod. 2010;25:1471-80.

20. Peng T, Coates R, Merriman G, Zhao Y, Maycock B. Testing the psychometric properties of Mandarin version of the fertility problem inventory (M-FPI) in an infertile Chinese sample. J Psychosom Obstet Gynaecol. 2011;32:173-81.

21. Jarvela IY, Sladkevicius P, Kelly S, Ojha K, Campbell S, Nargund G. Evaluation of endometrial receptivity during in-vitro fertilization using three-dimensional power Doppler ultrasound. Ultrasound Obstet Gynecol. 2005;26:765-9.

22. $\mathrm{Ng} \mathrm{EH}$, Chan CC, Tang OS, Yeung WS, Ho PC. Factors affecting endometrial and subendometrial blood flow measured by three-dimensional power Doppler ultrasound during IVF treatment. Hum Reprod. 2006;21:1062-9.

23. Raine-Fenning NJ, Campbell BK, Kendall NR, Clewes JS, Johnson IR. Quantifying the changes in endometrial vascularity throughout the normal menstrual cycle with three-dimensional power Doppler angiography. Hum Reprod. 2004 19:330-8.

24. Kupesic S, Bekavac I, Bjelos D, Kurjak A. Assessment of endometrial receptivity by transvaginal color Doppler and three-dimensional power Doppler ultrasonography in patients undergoing in vitro fertilization procedures. J Ultrasound Med. 2001;20:125-34

25. Schild RL, Holthaus S, d'Alquen J, Fimmers R, Dorn C, van Der Ven H, Hansmann M. Quantitative assessment of subendometrial blood flow by three-dimensionalultrasound is an important predictive factor of implantation in an invitro fertilization programme. Hum Reprod. 2000;15:89-94.
26. Tasker JG, Herman JP. Mechanisms of rapid glucocorticoid feedback inhibition of the hypothalamic-pituitary-adrenal axis. Ann Ny Acad Sci. 2011;14:398-406.

27. Engert V, Vogel S, Efanov SI, Duchesne A, Corbo V, Ali N, Pruessner JC. Investigation into the cross-correlation of salivary cortisol and alphaamylase responses to psychological stress. Psychoneuroendocrino. 2011; 36:1294-302.

28. Lilic V, Tubic-Pavlovic A, Radovic-Janosevic D, Petric A, Stefanovic M, Zivadinovic R. [Assessment of endometrial receptivity by color Doppler and ultrasound imaging]. Med Pregl. 2007;60:237-40.

29. Slayden OD, Rubin JS, Lacey DL, Brenner RM. Effects of keratinocyte growth factor in the endometrium of rhesus macaques during the luteal-follicular transition. J Clin Endocrinol Metab. 2000;85:275-85.

30. Coughlan C, Sinagra M, Ledger W, Li TC, Laird S. Endometrial integrin expression in women with recurrent implantation failure after in vitro fertilization and its relationship to pregnancy outcome. Fertil Steril. 2013;100:825-30.

31. Bernatova I, Csizmadiova Z, Kopincova J, Puzserova A. Vascular function and nitric oxide production in chronic social-stress-exposed rats with various family history of hypertension. J Physiol Pharmacol. 2007;58:487-501.

32. Lynch CD, Sundaram R, Maisog JM, Sweeney AM, Buck Louis GM. Preconception stress increases the risk of infertility: results from a couple-based prospective cohort study-the LIFE study. Hum Reprod. 2014;29:1067-75.

\section{Submit your next manuscript to BioMed Central and we will help you at every step:}

- We accept pre-submission inquiries

- Our selector tool helps you to find the most relevant journal

- We provide round the clock customer support

- Convenient online submission

- Thorough peer review

- Inclusion in PubMed and all major indexing services

- Maximum visibility for your research

Submit your manuscript at www.biomedcentral.com/submit
) Biomed Central 